\title{
Characterization of sonic hedgehog inhibition in gastric carcinoma cells
}

\author{
RUXUE BAI ${ }^{1}$, HONGCHUAN ZHAO ${ }^{1}$, XIANG ZHANG ${ }^{2}$ and SHIYU DU ${ }^{1}$ \\ ${ }^{1}$ Department of Gastroenterology, China-Japan Friendship Hospital, Chaoyang, Beijing 100029, P.R. China; \\ ${ }^{2}$ Department of Molecular and Cellular Biology, Baylor College of Medicine, Houston, TX 77030, USA
}

Received June 20, 2013; Accepted January 23, 2014

DOI: $10.3892 / \mathrm{ol} .2014 .1964$

\begin{abstract}
Aberrant activation of the sonic hedgehog (Shh) signaling pathway plays an important role in gastric cancer. The exact mechanisms defining how the Shh pathway promotes tumorigenesis or regulates its downstream targets remains elusive. In the present study, the effects of inhibiting the Shh signaling pathway in gastric cancer AGS cells was examined. It was identified that the Shh antagonist, cyclopamine, inhibited cancer proliferation, migration and invasion in a dose- and time-dependent manner. Additionally, it was revealed that several key targets that are activated by the Shh signaling pathway, Gli1 and CXCR4, were downregulated at an RNA and protein level by cyclopamine. The results from the present study may be of benefit in facilitating the development of novel therapeutic strategies to treat gastric cancer in human patients.
\end{abstract}

\section{Introduction}

The hedgehog signaling pathway is critical for it's role in normal cell differentiation and embryonic development, as well as in the pathological processes that drive cancer formation (1-3). The ligands of sonic hedgehog (Shh) bind to the transmembrane receptor, Patched (ptch) 1 and 2, to relieve the suppression of the transmembrane protein, Smoothened (Smo). This subsequently triggers the nuclear translocation of various transcription factors to activate downstream target genes $(2,4)$. In various types of cancer, including ovarian (5), lung $(6,7)$, breast (8), prostate (9), endometrial (10), skin (11) and gastrointestinal (12-14), aberrant activation of Smo genes and loss of function mutations in the ptch gene relieve the suppression of the Smo protein and trigger full-length Glil translocation into the nucleus, prompting excessive activation of downstream genes, including c-myc and vascular endothelial growth factor

Correspondence to: Dr Shiyu Du, Department of Gastroenterology, China-Japan Friendship Hospital, 2 Yinghua Dongjie, Chaoyang, Beijing 100029, P.R. China

E-mail: dushiyu1975@126.com

Key words: Sonic hedgehog, human gastric cancer cell, Gli1, CXCR4
(VEGF). It has also been demonstrated that inhibition of the Shh pathway by a Smo inhibitor, such as cyclopamine, slows or prevents the growth of tumor tissues (15-17).

In the case of gastric cancer cells, excessive Shh signaling activities are well known to affect cancer cell proliferation, migration and invasion, and overexpression of Shh was identified in intestinal metaplasia and stomach adenomas (18). In in vitro studies, the Shh pathway and downstream genes/proteins are highly involved in the proliferation and migration of various gastric cancer cell lines, including MKN1/7/45/74, MKN45 and AGS cells $(19,20)$. However, the exact mechanisms defining how the Shh pathway regulates gastric tumorigenesis remains elusive.

In the present study, via the application of cyclopamine, the Shh signaling pathway was inhibited in the human gastric cancer cell line, AGS, and the effect on cell proliferation, migration and invasion was evaluated. Furthermore, it was demonstrated that the molecular and cellular expression of key Shh signaling pathway-associated factors, Gli1 and CXCR4, were markedly downregulated by cyclopamine in AGS cells.

\section{Materials and methods}

Cell culture and treatment. Human gastric cancer cell line AGS was obtained from American Type Culture Collection (ATCC CRL-1739) and were maintained in RPMI-1640 medium supplemented with $10 \%$ fetal bovine serum (Invitrogen Life Technologies, Carlsbad, CA, USA) and $100 \mathrm{U} / \mathrm{ml}$ penicillin/streptomycin. The cells were cultured either with cyclopamine (5-100 $\mu \mathrm{M}$; Calbiochem, La Jolla, CA, USA) or without cyclopamine for 24,48 or $72 \mathrm{~h}$.

Cell proliferation assay. Cells were plated at a concentration of $2.5 \times 10^{4}$ cells $/ \mathrm{ml}$ of culture medium in 96 -well plates for 24 and $72 \mathrm{~h}$. Following the defined culture periods, an MTT assay (Sigma, St. Louis, MO, USA) was applied according to the manufacturer's instructions to calculate the volume of viable cells (21).

Apoptosis assay. Following in vitro culture for $24 \mathrm{~h}$, the gastric cancer cells, a total amount of $1 \times 10^{6}$, were collected in a binding buffer (10 mM HEPES/NaOH, $140 \mathrm{mM} \mathrm{NaCl}, 2.5 \mathrm{mM} \mathrm{CaCl}$ ) after washing with phosphate-buffered saline (PBS; 3x10 min). Fluorescence-activated cell sorting analysis for apoptosis was 
Table I. Cyclopamine induces apoptosis in gastric cancer cells.

\begin{tabular}{lccc}
\hline Parameter & Control & $50 \mu \mathrm{M}$ & $100 \mu \mathrm{M}$ \\
\hline Rate of apoptosis, 24 h & $1.52 \pm 0.51$ & $15.25 \pm 2.11^{\mathrm{a}}$ & $22.55 \pm 1.94^{\mathrm{a}}$ \\
Rate of apoptosis, 48 h & $3.15 \pm 0.63$ & $24.32 \pm 2.37^{\mathrm{a}}$ & $30.12 \pm 2.33^{\mathrm{a}}$ \\
\hline
\end{tabular}

${ }^{\mathrm{a}} \mathrm{P}<0.05$, as compared with the control.

conducted using an Annexin V-FITC/7-AAD kit according to the manufacturer's instructions (Beckman Coulter, Miami, FL, USA). The mixture was incubated for $10 \mathrm{~min}$ in a dark room at room temperature and the stained cells were immediately analyzed using a flow cytometer (Cell Lab Quanta SC; Beckman Coulter) to determine the percentage of apoptotic cells.

Invasion assay. Cancer cell migration/invasion was performed by a quantitative cell migration assay (ECM500; Chemicon, Temecula, CA, USA) according to the manufacturer's instructions. Warm Knockout DMEM (Sigma) in the amount of $200 \mu \mathrm{l}$ was applied to the extracellular matrix (ECM) layer to hydrate for $2 \mathrm{~h}$ at room temperature. AGS cells were then dislodged by trypsinization ( $0.25 \%$ trypsin; Sigma) and dispersed into a homogeneous single-cell suspension at the concentration of $5 \times 10^{5}$ cells $/ \mathrm{ml}$, followed by washing and resuspension in Knockout DMEM. Then, cell suspension of $200 \mu \mathrm{l}$ was allowed to adhere to the surface at $37^{\circ} \mathrm{C}$ for $60 \mathrm{~min}$. The migration mediums containing cyclopamine were then put into the bottom chamber. Following $24 \mathrm{~h}$ of incubation at $37^{\circ} \mathrm{C}, 5 \% \mathrm{CO}_{2}$ in air, the cells in the upper chamber were stained for $20 \mathrm{~min}$, and dissolved in 10\% acetic acid and the optical density (OD) was read at $560 \mathrm{~nm}$ on a standard reader.

Quantitative polymerase chain reaction ( $q P C R)$. A TRIzol reagent (Roche) was used to isolate total RNA from $5 \times 10^{6}$ cells according to the manufacturer's instructions. First-strand cDNA synthesis and amplification was conducted using an MBI Revert Aid First Strand cDNA Synthesis kit (MBI Fermentas, Amherst NY, USA). The qPCR was performed using an iQ5 Multicolor Real-Time PCR Detection system (Bio-Rad, Hercules, CA, USA). The cycle threshold values were read from the ABI 7000 software. The primers were: Forward, 5'-TCCTTTGGGGTCCAGCCTTG-3' and reverse, 5'-ATGCCTGTGGAGTTGGGGCT-3' for Gli1; forward, 5'-TCAGTCTGGACCGCTACCTG-3' and reverse, 5'-CCACCCACAAGTCATTGGGG-3' for CXCR4; and forward, 5'-AGGTCGGAGTCAACGGATTTG-3' and reverse, 5'-GTGATGGCATGGACTGTGGT-3' for GAPDH.

Western blot analysis. RIPA buffer $(50 \mathrm{mM}$ Tris, $150 \mathrm{mM}$ $\mathrm{NaCl}, 1 \%$ Triton $\mathrm{X}-100,0.1 \%$ sodium dodecyl sulfate and $1 \%$ Na-deoxycholate; $\mathrm{pH}$ 7.4) supplemented with protease inhibitor was used to collect the cell suspension for the western blot analysis and a Bio-Rad protein assay (Bio-Rad) was used to calculate the total protein concentrations. Briefly, the protein lysates were resolved by sodium dodecyl sulfate-polyacrylamide gel electrophoresis and transferred onto nitrocellulose membranes (Hybond ${ }^{\mathrm{TM}}$-P; Amersham Biosciences, Piscataway, NJ, USA). The membrane was blocked using $0.2 \%$ Tween-20 and 5\% non-fat dry milk in PBS. The lysates were incubated with a primary antibodies: GLI-1 rabbit polyclonal anti human IgG (H-300, Santa Cruz Biotechnology, Inc., Santa Cruz, CA, USA) and CXCR-4 rabbit polyclonal IgG anti-human (H-118, Santa Cruz Biotechnology, Inc.) and a horseradish peroxidase-labeled rabbit IgG secondary antibody (Santa Cruz Biotechnology, Inc.) and detected using X-ray film.

Statistical analysis. Data were calculated in triplicate and expressed as the mean \pm standard error of the mean. Comparisons were made using either student's t-test or one-way analysis of variance post hoc tests. $\mathrm{P}<0.05$ was considered to indicate a statistically significant result.

\section{Results}

Inhibition of gastric cancer cell proliferation by cyclopamine. AGS cells were cultured with or without cyclopamine for 24,48 and $72 \mathrm{~h}$, and the effect of cyclopamine on cell proliferation was measured (Fig. 1). The results demonstrated that when AGS cells were treated with 5 or $10 \mu \mathrm{M}$ of cyclopamine for 24,48 or $72 \mathrm{~h}$, the proliferation densities were unaffected, as compared with the control conditions $(\mathrm{P}>0.05)$. This indicated that the application of cyclopamine at lower concentrations did not alter the cell proliferation rate. However, while AGS cells that were treated with 50 or $100 \mu \mathrm{M}$ cyclopamine for 48 or $72 \mathrm{~h}$, respectively, cell proliferation was significantly inhibited, indicating that a higher concentration of cyclopamine inhibited the growth of AGS cells in a dose-dependent manner $(\mathrm{P}<0.05)$.

Induction of apoptosis in gastric cancer cells by cyclopamine. Secondly, the effects of cyclopamine on the AGS cells were examined. The cells were either untreated (control) or treated with cyclopamine (50 or $100 \mu \mathrm{M}$ ) for 24 or 48 $\mathrm{h}$, followed by annexin $\mathrm{V}$ staining. The results demonstrated that high concentrations of cyclopamine $(50$ or $100 \mu \mathrm{M})$ induced significant apoptosis in AGS cells (Table I).

Inhibition of cell invasion in gastric cancer cells by cyclopamine. A characteristic feature of gastric cancer cells is their aggressive ability to filtrate and invade a reconstituted basement membrane. The effect of cyclopamine on the cellular invasion of human gastric cancer cells was assessed in the present study. The cancer cells were either untreated (control) 


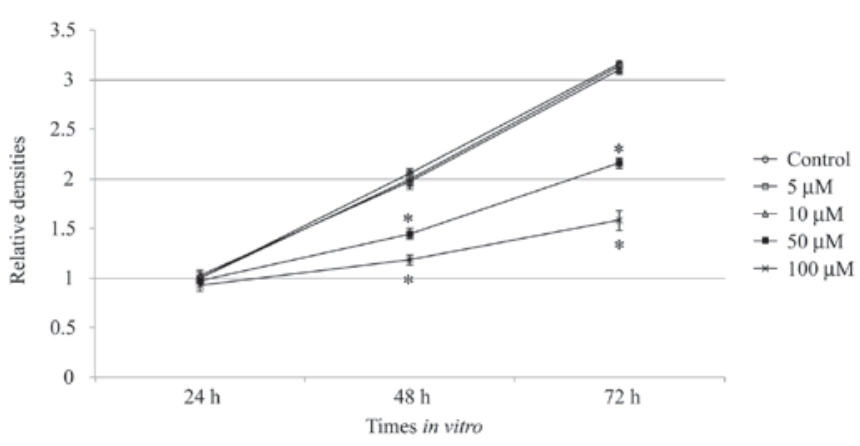

Figure 1. Cyclopamine inhibits AGS cell proliferation. AGS cells were treated without cyclopamine (control) or with varying concentrations of cyclopamine $(5,10,50$ and $100 \mu \mathrm{M})$ for 24,48 and $72 \mathrm{~h}$, and the cell densities were calculated and compared with the density at $24 \mathrm{~h}$ in the control condition. One-way ANOVA demonstrated 50 and $100 \mu \mathrm{M}$ of cyclopamine significantly slowed cell proliferation following 48 or $72 \mathrm{~h}$ in culture. ${ }^{*} \mathrm{P}<0.05$ vs. control.

A

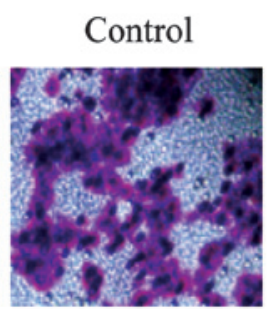

$50 \mu \mathrm{M}$ cyclopamine

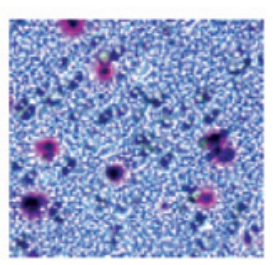

B

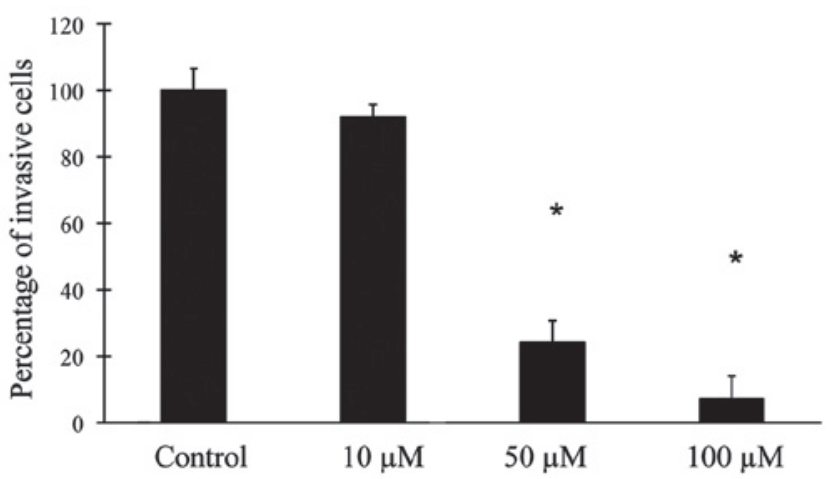

Figure 2. AGS cell invasion was inhibited by cyclopamine. (A) A transwell assay was used to examine the invasion of gastric cancer cells at varying concentrations of cyclopamine $(10,50$ and $100 \mu \mathrm{M})$. The cells were stained with $0.1 \%$ crystal violet. (B) Cyclopamine, at concentrations of 10,50 and $100 \mu \mathrm{M}$, significantly diminished the capability of invasion in gastric cancer cells. ${ }^{*} \mathrm{P}<0.05$ vs. control.

or treated with cyclopamine at concentrations of 10,50 and $100 \mu \mathrm{M}$, and maintained in the culture medium for $24 \mathrm{~h}$ (Fig. 2). When treated with $10 \mu \mathrm{M}$ of cyclopamine, AGS cells demonstrated a similar rate of invasion, as compared with that of the control condition $(\mathrm{P}>0.05)$. However, with higher

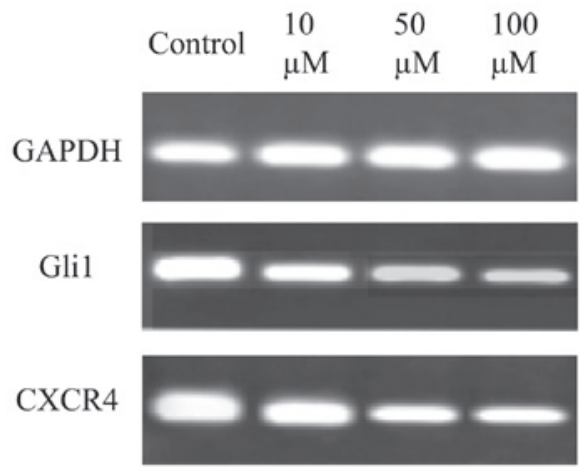

Figure 3. Cyclopamine downregulated Shh-associated gene expression in AGS cells. Following $24 \mathrm{~h}$ in culture, cyclopamine downregulated mRNA expression of Gli1 and CXCR4 in gastric cancer cells at concentrations of 10 , 50 and $100 \mu \mathrm{M}$. Shh, sonic hedgehog.

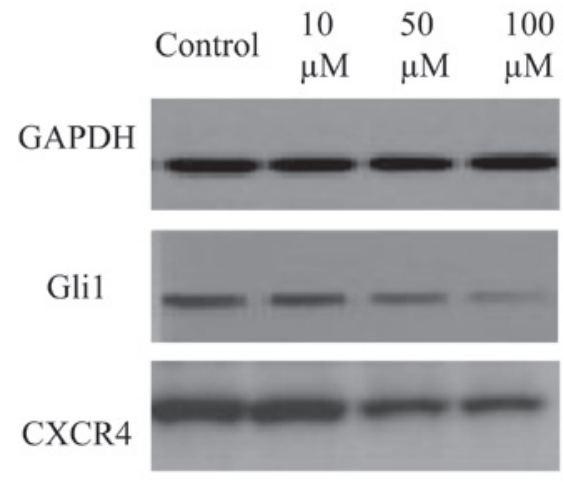

Figure 4. Cyclopamine downregulated Shh-associated protein expression in AGS cells. Western blot analysis revealed that, following $24 \mathrm{~h}$ in culture, the protein expression levels of Gli1 and CXCR4 were downregulated in gastric cancer cells by 50 or $100 \mu \mathrm{M}$ cyclopamine.

concentrations of cyclopamine (50 and $100 \mu \mathrm{M})$, the baseline invasions were significantly inhibited. This response was dose-dependent as the greater the concentration of cyclopamine was, the higher the degree of inhibition it induced on cancer cell migration $(\mathrm{P}<0.05)$.

Downregulation of Shh-associated factors by cyclopamine in gastric cancer cells. The effects of cyclopamine on gene regulation in AGS cells are demonstrated in Fig. 3. AGS cells were treated with 10,50 and $100 \mu \mathrm{M}$ cyclopamine for $24 \mathrm{~h}$. This identified that the higher concentrations of cyclopamine (50 and $100 \mu \mathrm{M}$ ) markedly downregulated the gene expression of Gli1 and CXCR4 in the gastric cancer cells.

Cyclopamine downregulated Shh-associated proteins in AGS cells. The effects of cyclopamine on Shh-related protein expression in AGS cells are presented in Fig. 4. The results were consistent with the gene expression results, as higher concentrations of cyclopamine (50 and $100 \mu \mathrm{M}$ ) downregulated the protein expression of Gli1 and CXCR4 in the gastric cancer cells.

\section{Discussion}

The Shh signaling pathway is important in cell differentiation and maturation $(1-3,22)$. However, aberrant activation of the 
Shh pathway results in the proliferation of various cancer cell types, including lung, pancreatic and gastric $(5,8,23-25)$.

While the mechanisms of the Shh signaling pathway in promoting gastric tumor formation remain elusive, and the downstream targeting genes continue to be largely unknown, recent studies have indicated that various key factors, including Gil1 and CXCR4, are closely associated with these pathological processes. These studies identified that the chemokine receptor, CXCR4 and its cognate ligand, CXCL12 were expressed in cancerous tissues and possibly modulated the migration and invasion of tumors in prostate, endometrial and breast cancer (26-29). The in vivo and in vitro studies have identified that CXCR4 was expressed in gastric carcinoma and gastric cancer cell lines, and correlated with the late developmental stages of lymph node cancer (30).

In the present study, it was demonstrated that, following the inhibition of the Shh pathway through the application of cyclopamine, the proliferation rates and migration capacities in gastric cancer cells were significantly reduced in response to high concentrations of the compound. In addition, it was revealed that the gene and protein expression levels of Gli1 and CXCR4 were consistently downregulated in the gastric cancer cells when high concentrations of cyclopamine were applied. These results were consistent with previous studies that demonstrated that Gli1 and CXCR4 contributed to tumorigenesis in types of cancer other than gastric $(23,31,32)$. In conclusion, the results of the present study provide invaluable insights into the mechanisms of Shh signaling for the regulation of gastric cancer cell growth in vitro and these data may ultimately facilitate the development of novel therapeutic targets for the treatment gastric of cancer in human patients.

\section{References}

1. Hooper JE and Scott MP: Communicating with Hedgehogs. Nat Rev Mol Cell Biol 6: 306-317, 2005.

2. Ingham PW and McMahon AP: Hedgehog signaling in animal development: paradigms and principles. Genes Dev 15 3059-3087, 2001.

3. Pasca di Magliano M and Hebrok M: Hedgehog signalling in cancer formation and maintenance. Nat Rev Cancer 3: 903-911, 2003.

4. Bale AE and Yu KP: The hedgehog pathway and basal cell carcinomas. Hum Mol Genet 10: 757-762, 2001.

5. Liao X, Siu MK, Au CW, et al: Aberrant activation of hedgehog signaling pathway in ovarian cancers: effect on prognosis, cell invasion and differentiation. Carcinogenesis 30: 131-140, 2009.

6. Watkins DN, Berman DM, Burkholder SG, Wang B, Beachy PA and Baylin SB: Hedgehog signalling within airway epithelia progenitors and in small-cell lung cancer. Nature 422: 313-317, 2003.

7. Gialmanidis IP, Bravou V, Amanetopoulou SG, Varakis J, Kourea $\mathrm{H}$ and Papadaki H: Overexpression of hedgehog pathway molecules and FOXM1 in non-small cell lung carcinomas. Lung Cancer 66: 64-74, 2009.

8. ten Haaf A, Bektas N, von Serenyi S, et al: Expression of the glioma-associated oncogene homolog (GLI) 1 in human breast cancer is associated with unfavourable overall survival. BMC Cancer 9: 298, 2009.

9. Karhadkar SS, Bova GS, Abdallah N, et al: Hedgehog signalling in prostate regeneration, neoplasia and metastasis. Nature 431: 707-712, 2004

10. Feng YZ, Shiozawa T, Miyamoto T, et al: Overexpression of hedgehog signaling molecules and its involvement in the proliferation of endometrial carcinoma cells. Clin Cancer Res 13: 1389-1398, 2007.
11. Daya-Grosjean L and Couvé-Privat S: Sonic hedgehog signaling in basal cell carcinomas. Cancer Lett 225: 181-192, 2005.

12. Berman DM, Karhadkar SS, Maitra A, et al: Widespread requirement for Hedgehog ligand stimulation in growth of digestive tract tumours. Nature 425: 846-851, 2003.

13. Mori Y, Okumura T, Tsunoda S, Sakai Y and Shimada Y: Gli-1 expression is associated with lymph node metastasis and tumor progression in esophageal squamous cell carcinoma. Oncology 70: 378-389, 2006.

14. Qualtrough D, Buda A, Gaffield W, Williams AC and Paraskeva C: Hedgehog signalling in colorectal tumour cells: induction of apoptosis with cyclopamine treatment. Int J Cancer 110: 831-837, 2004.

15. Chen JK, Taipale J, Cooper MK and Beachy PA: Inhibition of Hedgehog signaling by direct binding of cyclopamine to Smoothened. Genes Dev 16: 2743-2748, 2002.

16. Chen JK, Taipale J, Young KE, Maiti T and Beachy PA: Small molecule modulation of Smoothened activity. Proc Natl Acad Sci USA 99: 14071-14076, 2002.

17. Lin TL and Matsui W: Hedgehog pathway as a drug target: Smoothened inhibitors in development. Onco Targets Ther 5: 47-58, 2012.

18. Lee SY, Han HS, Lee KY, et al: Sonic hedgehog expression in gastric cancer and gastric adenoma. Oncol Rep 17: 1051-1055, 2007.

19. Ohta M, Tateishi K, Kanai F, et al: p53-Independent negative regulation of $\mathrm{p} 21$ /cyclin-dependent kinase-interacting protein 1 by the sonic hedgehog-glioma-associated oncogene 1 pathway in gastric carcinoma cells. Cancer Res 65: 10822-10829, 2005.

20. Fukaya M, Isohata N, Ohta $\mathrm{H}$, et al: Hedgehog signal activation in gastric pit cell and in diffuse-type gastric cancer. Gastroenterology 131: 14-29, 2006.

21. Fan XG, Kelleher D, Fan XJ, Xia HX and Keeling PW: Helicobacter pylori increases proliferation of gastric epithelial cells. Gut 38: 19-22, 1996.

22. McMahon AP, Ingham PW and Tabin CJ: Developmental roles and clinical significance of hedgehog signaling. Curr Top Dev Biol 53: 1-114, 2003.

23. Yoo YA, Kang MH, Kim JS and Oh SC: Sonic hedgehog signaling promotes motility and invasiveness of gastric cancer cells through TGF-beta-mediated activation of the ALK5-Smad 3 pathway. Carcinogenesis 29: 480-490, 2008.

24. Nagai S, Nakamura M, Yanai K, et al: Glil contributes to the invasiveness of pancreatic cancer through matrix metalloproteinase-9 activation. Cancer Sci 99: 1377-1384, 2008.

25. Feldmann G, Dhara S, Fendrich V, et al: Blockade of hedgehog signaling inhibits pancreatic cancer invasion and metastases: a new paradigm for combination therapy in solid cancers. Cancer Res 67: 2187-2196, 2007.

26. Raman D, Baugher PJ, Thu YM and Richmond A: Role of chemokines in tumor growth. Cancer Lett 256: 137-165, 2007.

27. Salvucci O, Bouchard A, Baccarelli A, et al: The role of CXCR4 receptor expression in breast cancer: a large tissue microarray study. Breast Cancer Res Treat 97: 275-283, 2006.

28. Kodama J, Hasengaowa, Seki N, Kusumoto T and Hiramatsu Y: Expression of the CXCR4 and CCR7 chemokine receptors in human endometrial cancer. Eur J Gynaecol Oncol 28: 370-375, 2007.

29. Engl T, Relja B, Marian D, et al: CXCR4 chemokine receptor mediates prostate tumor cell adhesion through alpha5 and beta3 integrins. Neoplasia 8: 290-301, 2006.

30. Lee HJ, Kim SW, Kim HY, et al: Chemokine receptor CXCR4 expression, function, and clinical implications in gastric cancer. Int J Oncol 34: 473-480, 2009.

31. Yoon JW, Gilbertson R, Iannaccone S, Iannaccone P and Walterhouse D: Defining a role for Sonic hedgehog pathway activation in desmoplastic medulloblastoma by identifying GLI1 target genes. Int J Cancer 124: 109-119, 2009.

32. Katoh M: Integrative genomic analyses of CXCR4: transcriptional regulation of CXCR4 based on TGFbeta, Nodal, Activin signaling and POU5F1, FOXA2, FOXC2, FOXH1, SOX17, and GFI1 transcription factors. Int J Oncol 36: 415-420, 2010. 